\title{
OPTIMASI SISTEM PENJADWALAN DENGAN IMPLEMENTASI ALGORITMA WELCH POWELL PADA SISTEM PENJADWALAN CUSTOMER SERVICE DI GERAI INDOSAT OOREDOO CABANG KUTA
}

\author{
L.Virginayoga Hignasari ${ }^{1}$ \\ ${ }^{1}$ Program Studi Teknik Industri, Fakultas Teknik, Universitas Mahendradatta Bali \\ JI. Ken Arok No 12, Peguyangan Denpasar Utara, Bali 80115 \\ Email : ginahignasari@gmail.com
}

\begin{abstract}
Abstrak - Tujuan dari penelitian ini adalah untuk menyelesaiakan permasalahan terkait optimasi sistem penjadwalan customer service di Gerai Indosat Ooredoo Cabang Kuta dengan mengimplementasikan konsep pewarnaan graf yaitu dengan aplikai algoritma Welch Powell. Penelitian ini merupakan penelitian studi kasus. Data diperoleh dari hasil observasi dan wawancara. Data yang dianalisis adalah sistem penjadwalan customer service yang sudah ada sebelumnya. Sistem penjadwalan yang diperoleh akan dianalisis lebih lanjut dengan menggunakan algoritma Welch Powell untuk menyelesaikan permasalahan terkait dengan pembentukan tim mobile selling dan penjadwalanya. Sebelum dianalisis dengan menggunakan algoritma Welch Powell, sistem penjadwalan terlebih dahulu direpresentasikan dalam bentuk graf. Adapaun algoritma Welch Powell adalah 1) Urutkan simpul-simpul dari G dalam derajat yang menurun; 2) Gunakan satu warna untuk mewarnai simpul pertama (yang mempunyai derajat tertinggi) dan simpul-simpul lain yang tidak bertetanga dengan simpul pertama ini; 3) Mulai lagi dengan simpul berderajat tertinggi berikutnya di dalam daftar terurut yang belum diwarnai dan ulangi proses pewranaan simpul dengan menggunakan warna kedua. Berdasarkan hasil analisis, dari jumlah customer service yang ada dapat dibentuk menjadi tiga tim dengan jadwal mobile selling secara bergantian dalam satu minggu. Hal ini lebih efisien daripada sistem penjadwalan sebelumnya yang mentukan tim mobile selling berdasarkan kesamaan shift kerja karyawan. Berdasarkan hal tersebut, implementasi algoritma Welch Powell dapat menyelesaikan permasalahan optimasi sistem penjadwalan di divisi Customer Service Indosat Ooredoo Cabang Kuta secara teoritis.
\end{abstract}

Kata Kunci : jadwal, graf, optimasi, welch powell

\begin{abstract}
Abstact- The purpose of this research was to solve the problems related to the optimization of the customer service scheduling system in Indosat Ooredoo Office Kuta Branch by implementing the concept of graph coloring, namely the application of the Welch Powell algorithm. This research was a case study. Data obtained from observations and interviews. The data analyzed is a pre-existing customer service scheduling system. The scheduling system obtained will be analyzed further by using Welch Powell's algorithm to solve problems related to the formation of mobile selling teams and its schedule. Before being analyzed using the Welch Powell algorithm, the scheduling system is represented in graph form. There was a Welch Powell algorithm that is 1) Sort the vertices of $G$ in decreasing degrees; 2) Use one color to color the first node (which has the highest degree) and other vertices that do not match the first node; 3) Start again with the next highest degree node in the ordered list that has not been colored and repeat the process of node transfer using the second color. Based on the results of the analysis, the number of existing customer services can be formed into three teams with alternating mobile selling schedules in one week. This is more efficient than the previous scheduling system that determined the mobile selling team based on the employee's work shift. Based on this, the implementation of the Welch Powell algorithm can solve the problem of scheduling system optimization in the Indosat Ooredoo Customer Service Division of the Kuta Branch theoretically.
\end{abstract}

Keywords: schedule, graph, optimization, welch powell

\section{PENDAHULUAN}

Setiap perusahaan yang bergerak dalam bidang pelayanan tentu tidak lepas dari adanya divisi front office ataupun customer service. Tidak jarang perusahaan mengalokasikan banyak karyawan yang ditempatkan pada divisi tersebut. Hal ini bertujuan agar perusahaan mampu memberikan pelayanan terbaik kepada customer. Bagi beberapa perusahaan yang memiliki waktu pelayanan lebih dari jam operasional kantor, tentu akan menerapkan 
sistem shift atau pembagian waktu kerja. Hal ini dilakukan agar setiap karyawan tidak mendapatkan jam kerja yang melebihi dari aturan yang berlaku. Terkait dengan hal tersebut, penjadwalan jam kerja karyawan merupakan salah satu hal yang sangat penting. Dalam membuat jadwal setiap karyawan, beberapa hal harus diperhatikan agar tidak ada karyawan yang mendapatkan jam kerja lebih banyak dan tidak ada jadwal karyawan yang berbenturan. Oleh sebab itu, dalam penyusunan jadwal harus dirancang dan dirumuskan seoptimal mungkin.

Penjadwalan merupakan salah satu permasalahan optimasi. Baker menyebutkan bahwa penjadwalan merupakan alokasi dari sumber daya terhadap waktu untuk menghasilkan sebuah kumpulan pekerjaan (dalam Sholihan, 2013). Penjadwalan adalah suatu proses pengalokasian sumber daya yang ada untuk menghasilkan suatu jadwal yang teratur dan sesuai dengan permintaan (Riau, 2017). Sistem penjadwalan dikatakan optimal apabila setiap sumber daya mendapatkan proporsi waktu yang sama dan tidak ada sumber daya yang saling tumpang tindih. Dalam merancang sebuah sistem penjadwalan di sebuah perusahaan, diperlukan pemikiran yang matang untuk dapat memetakan seluruh komponen penjadwalan ke dalam timeslot dengan mempertimbangkan semua batasan yang ada.

Beberapa permasalahan yang biasa timbul pada sistem penjadwalan karyawan di suatu perusahaan adalah seringya terjadi jadwal yang berbenturan dan jumlah proporsi jam kerja tiap karyawan berbeda-beda. Permalasahan tersebut juga terkadang dialami pada divisi customer service di Gerai Indosat Ooredoo cabang Kuta. Dengan lamanya jam opersional gerai yaitu dimulai pukul 08.00 wita samapi dengan 20.00 wita dengan waktu pelayanan dibuka setiap hari mengakibatkan harus disusunya sistem penjadwalan yang sangat optimal. Selain itu pelayanan tidak hanya difokuskan di galeri, namun berdasarkan kebijakan perusahaan Indosat Ooredoo cabang Kuta, untuk meningkatkan penjualan, setiap customer service juga melakukan kegiatan mobile seliing. Mobile selling merupakan kegiatan promosi atau penawaran produk dan benefit layanan kepada customer di luar Galeri. Karena setiap CS memiliki target penjualan, maka kegiatan mobile selling ini sangat penting untuk dijalankan, mengingat terbatasnya customer yang datang ke galeri. Tentunya dari target tersebut terdapat pula insentive bagi para CS yang mampu mencapai target setiap bulanya. Oleh sebab itu terkadang, beberapa CS lebih gencar melakukan mobile selling untuk memperoleh customer. Dalam pelaksanaanya mobile selling, setiap CS dibagi lagi dalam timtim kecil dan di atur sedemikian rupa agar tidak mengganggu proses pelayanan di Galeri. Awalnya pembentukan tim mobile selling ditetapkan dengan ketentuan tim terdiri dari 2 orang CS yang berada dalam shift yang sama. Pada pelaksnaan secara real, dengan adanya beberapa CS yang melakukan mobile selling membuat alur dan jadwal kerja CS menjadi tidak teratur. Adapaun beberapa temuan berdasarkan hasil observasi adalah, CS yang melakukan kegiatan mobile selling adalah CS yang bekerja dalam shift yang sama. Dengan kondisi tersebut terkadang membuat pelayanan di galeri terutama pada saat jamjam istirahat menjadi sedikit kacau, karena kurangya personil CS yang menghandle customer. Tentunya hal tersebut apabila dibiarkan berlarut larut akan berdampak pada menurunya kualitas pelayanan dana berujung pada menurunya tingkat kepuasan customer.

Proses pembentukan tim secara manual dengan jadwal karyawan yang kompleks biasanya akan memerlukan waktu yang cukup lama dan memungkinkan terjadinya pelanggaran constraint akibat human error. Oleh sebab itu, dalam pembentukan tim dan penyusunan jadwal dilakukan melalui beberapa iterasi perbaikan. Adapaun fungsi tujuannya adalah memenuhi sejumlah constraint penjadwalan, seperti menghindari terjadinya benturan jadwal antara karyawan satu dengan yang lainnya. Untuk menghindari benturan jadwal antara karyawan yang satu dengan yang lainnya, dalam pembentukan tim disesuaikan dengan jadwal setiap customer service. Salah satu alternatif solusi untuk mengatasi masalah dalam penjadwalan tersebut adalah dengan menerapkan salah satu konsep dalam bidang ilmu matematika. Bidang ilmu yang dapat digunakan sebagai alternatif solusi adalah matematika diskrit. Di dalam kajian ilmu matematika diskrit, teori graf khususnya pada konsep pewarnaan graf mampu menyelesaikan permasalahan penjadwalan tersebut.

Graf adalah himpunan titik (vertices) dan himpunan ruas garis (edges). Titik-titik dalam sebuah graf dihubungkan satu sama lain melalui ruas. Suatu graf $G$ terdiri dari himpunan tidak kosong dari elemen-elemen yang disebut titik (vertices) dan suatu daftar pasangan node yang tidak terurut disebut ruas (edge). Himpunan vertices dari suatu graf $\mathrm{G}$ dinotasikan dengen $V(G)$ sedangkan daftar himpunan edges dari graph $G$ dinotasikan dengen $E(G)$. Untuk selanjutnya, suatu graph $\mathrm{G}$ dapat dinotasikan dengan $\mathrm{G}=(\mathrm{V}, \mathrm{E})$ yang 
artinya graf $G$ mempunyai $V$ vertices dan $E$ edges (Hignasari, 2018).

Dalam teori graf perwanaan merupakan suatu bentuk perlabelan graf dengan cara memberikan warna pada elemen graf yang akan dijadikan subjek dalam memahami constraint permasalahan (Mahardika, 2017). Dengan cara ada tiga macam persoalan perwarnaan graf (Graph Colouring) yaitu perwarnaan simpul, perwarnaan sisi, dan perwarnaan wilayah atau region (Munir, 2005).

Penyelesaian kasus penjadwalan pada haikatnya adalah berupaya untuk mengalokasikan sejumlah aktivitas yang mengandung constraint atau batasan ke dalam timeslot (matriks ruang dan waktu) (Astuti, 2011). Jumlah timeslot yang tersedia memiliki batasan, baik berupa jumlah ruang, maupaun waktu penggunannya. Oleh karena itu, penjadwalan yang baik haruslah dapat menyesuaikan sejumlah keterbatasan sumber daya agar seluruh aktivitas dapat tetap terlaksanan tanpa melanggar batasan yang ada (Astuti, 2011). Sesuai dengan hal tersebut pewarnaan graf mengakomodasi dengan bilangan kromatik. Bilangan kromatik graf $\mathrm{G}$ adalah jumla warna minimum yang dapat digunakan untuk mewarnao simpul (vertex V). Terdapat banyak algoritma yang dapat digunakan untuk menyelesaikan permasalahan-permasalahan pewarnaan simpul graf misalnya Algoritma Welch-Powell, Algoritma Backtracking, dan Algoritma Recursive Largest First (Sianipar, 2014). Salah satu alternatif solusi yang dapat digunakan untuk permasalahan penjadwalan adalah dengan menggunakan algoritma Welch Powell.

Algoritma Welch Powell merupakan salah satu algoritma pewarnaan graf yang melakukan pewarnaan berdasarkan derajat tertinggi dari simpul-simpulnya atau disebut Largest Degreee Ordering (LDO) (Astuti, 2011). Algoritma Welch Powell dapat digunakan untuk mewarnai sebuah graf $G$ secara efisien. Algoritma Welch Powell tidak selalu memberikan jumlah warna minimum namun semakin minimal warna yang dihasilkan maka semakin baik sebuah pewarnaan graf tersebut (Liyandari dkk, 2014). Berdasarkan hal di atas, penulis tertarik untuk mengaplikasikan algoritma Welch Powell untuk menyelesaikan permasalahan terkait pembentukan tim dan penyusunan jadwal tim divisi Customer Service Gerai Indosat Ooredoo Cabang Kuta. Dengan implemetasi algoritma Welch Powell secara teoritis diharapkan mampu memberikan solusi yang tepat terkait masalah optimasi dalam sistem penjadwalan.

\section{METODE PENELITIAN}

Penelitian ini merupakan penelitian studi kasus. Dalam penelitian ini, peneliti mengambil sampel sistem penjadwalan karyawan divisi Customer service di PT Indosat Ooredoo cabang Kuta. Jumlah customer service di cabang tersebut adalah 13 orang dengan pembagian kerja masingmasing CS bekerja 7 jam. Pelayanan dilakukan setiap hari dari pukul 08.00 wita 20.00 wita sehingga untuk mengefisienkan waktu kerja CS maka waktu pelayanan dibagi menjadi 3 shift yaitu shift 1 pada pukul 08.00 wita - 15.00 wita, shift 2 pada pukul 09.00 wita - 16.00 wita dan shift 3 pada pukul 11.00 wita - 20.00 wita. Dari data tersbut, kemudian akan ditentukan tim mobile selling. Tim mobile selling dibentuk seoptimal mungkin karena terkait dengan masalah pembagian kendaraan operasional kendaraan dan agar tidak menganggu proses pelayanan di Gerai. Untuk menetukan pembagian tim dan jadwal dari tim mobile selling akan dianalisis menggunakan teori pewarnaan graf yaitu dengan aplikasi algoritma Welch Powel. Adapun algoritma Welch Powell adalah sebagai berikut:

1. Urutkan simpul-simpul dari $G$ dalam derajat yang menurun.

2. Gunakan satu warna untuk mewarnai simpul pertama (yang mempunyai derjat tertinggi) dan simpul-simpul lain yang tidak bertetanga dengan simpul pertama ini.

3. Mulai lagi dengan simpul berderajat tertinggi berikutnya di dalam daftar terurut yang belum diwarnai dan ulangi proses pewranaan simpul dengan mengunakan warna kedua.

4. Ulangi menggunaan warna-warna sampai semua simpul telah diwarnai. (Astuti, 2011).

Berikut diagram alir dari algoritma Welch Powell.

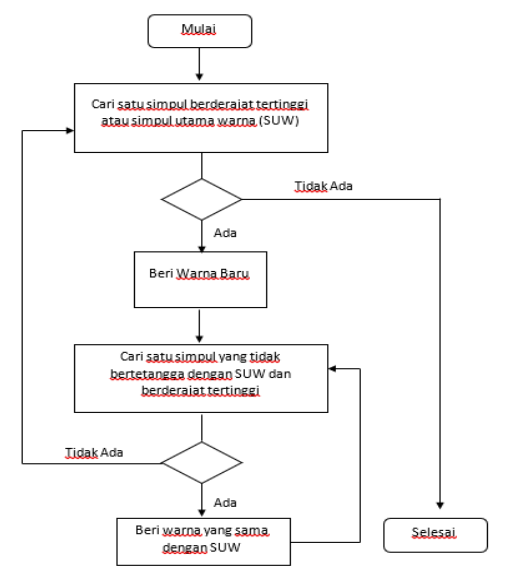

Gambar 2. Graf Jadwal Kerja Customer Service Cabang Kuta 


\section{HASIL DAN PEMBAHASAN}

Berdasarkan data yang diperoleh adapaun dapat dirinci jadwal kerja customer service yang sudah berjalan adalah sebagai

Tabel 1. Jadwal Customer Service Cabang Kuta

\begin{tabular}{|c|c|c|c|c|c|c|c|c|c|c|c|c|c|c|c|c|c|c|c|c|c|}
\hline \multirow{2}{*}{ CS } & \multicolumn{3}{|c|}{ Senin } & \multicolumn{3}{|c|}{ Selasa } & \multicolumn{3}{|c|}{ Rabu } & \multicolumn{3}{|c|}{ Kamis } & \multicolumn{3}{|c|}{ Jumat } & \multicolumn{3}{|c|}{ Sabtu } & \multicolumn{3}{|c|}{ Mlnggu } \\
\hline & 1 & 2 & 3 & 1 & 2 & 3 & 1 & 2 & 3 & 1 & 2 & 3 & 1 & 2 & 3 & 1 & 2 & 3 & 1 & 2 & 3 \\
\hline$A$ & V & & & V & & & & & V & & V & & & V & & & & & & & \\
\hline B & $\mathrm{V}$ & & & V & & & & & V & V & & & & V & & & & & & & \\
\hline C & V & & & V & & & & & V & & & & & & & $\mathrm{V}$ & & & & V & \\
\hline D & V & & & V & & & & & & & & & & & V & V & & & V & & \\
\hline$E$ & & $\mathrm{~V}$ & & & V & & $\mathrm{V}$ & & & $\mathrm{V}$ & & & & & V & & & & & & \\
\hline $\mathrm{F}$ & & & & & & & & & V & & V & & & & V & V & & & & & V \\
\hline $\mathrm{G}$ & & V & & & $\mathrm{V}$ & & & & & & & & & & $\mathrm{V}$ & $\mathrm{V}$ & & & & & $\mathrm{V}$ \\
\hline $\mathrm{H}$ & & & V & & & V & V & & & $\mathrm{V}$ & & & & & & & & & & $\mathrm{V}$ & \\
\hline I & & & & & & V & V & & & V & & & V & & & & V & & & & \\
\hline $\mathrm{J}$ & & & & & & & $\mathrm{V}$ & & & & & $\mathrm{V}$ & V & & & & V & & $\mathrm{V}$ & & \\
\hline $\mathrm{K}$ & & & V & & & & & & & & & V & V & & & & & V & V & & \\
\hline $\mathrm{L}$ & & & $\mathrm{V}$ & & & V & & V & & & & & & & & & & $\mathrm{V}$ & $\mathrm{V}$ & & \\
\hline $\mathrm{M}$ & & & & & & & & V & & & & V & V & & & & & V & & & $\mathrm{V}$ \\
\hline
\end{tabular}

Keterangan :

1 : Sinft Pagi Pukul 08.00 wita -15.00 wita

2 : Sihft Middle Pukul 09.00 wita -16.00 wita

3 : Sihft Siang Pukul 11.00 wita -20.00 wita

4. Tabel diblok : Libur

Berikut representasi tabel diatas dalam bentuk matriks yang disajikan pada Tabel 2.

Tabel 2. Matriks Jadwal Customer Service Cabang Kuta

\begin{tabular}{|l|l|l|l|l|l|l|l|l|l|l|l|l|l|}
\hline \multirow{2}{*}{ Hari } & \multicolumn{9}{|l|}{ Customer Service } \\
\cline { 2 - 16 } & A & B & C & D & E & F & G & H & I & J & K & L & M \\
\hline Senin & 1 & 1 & 1 & 1 & 2 & - & 2 & 3 & - & - & 3 & 3 & - \\
\hline Selasa & 1 & 1 & 1 & 1 & 2 & - & 2 & 3 & 3 & - & - & 3 & - \\
\hline Rabu & 3 & 3 & 3 & - & 1 & 3 & - & 1 & 1 & 1 & - & 2 & 2 \\
\hline Kamis & 2 & 1 & - & - & 1 & 2 & - & 1 & 1 & 3 & 3 & - & 3 \\
\hline Jumat & 2 & 2 & - & 3 & 3 & 3 & 3 & - & 1 & 1 & 1 & - & 1 \\
\hline Sabtu & - & - & 1 & 1 & - & 1 & 1 & - & 2 & 2 & 3 & 3 & 3 \\
\hline Minggu & - & - & 2 & 1 & - & 3 & 3 & 2 & - & 1 & 1 & 1 & 3 \\
\hline
\end{tabular}


Dari matriks tersebut akan direpresentasikan dalam model graf. Adapun ketentuan dalam pembuatan graf berdasarkan data di atas adalah sebagai berikut :

1. Customer service akan menjadi titiktitik simpul dalam graf

2. Customer service yang memiliki shift yang sama di masing-masing hari saling dihubungkan.

Berikut hasil representasi tabel matriks dalam bentuk graf yang disajikan dalam Gambar 2.

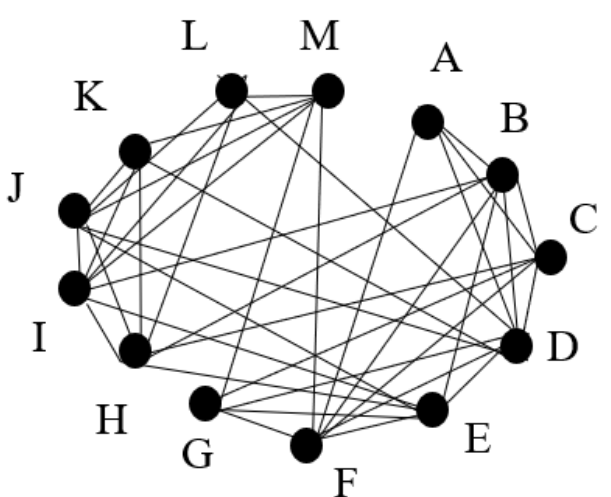

Gambar 2. Graf Jadwal Kerja Customer Service Cabang Kuta

Berdasarkan graf di atas dapat dibuat tabel Ketetanggan simpul graf dan derajatnya yang disajikan pada Tabel 3 .

Tabel 3. Ketetanggaan Simpul Graf dan Derajatnya

\begin{tabular}{|c|l|c|}
\hline Verteks ( Simpul ) & \multicolumn{1}{|c|}{ Verteks Tetangga } & Derajat \\
\hline VA & VB, VC, VD, VF & 4 \\
\hline VB & VA, VC, VD, VE, VF, VH, VI & 6 \\
\hline VC & VA, VB, VD, VF, VG, VH & 9 \\
\hline VD & VA, VB, VC, VE, VF, VG, VJ, VK, VL & 6 \\
\hline VE & VG, VH, VI, VJ, VF, VB & 6 \\
\hline VF & VA, VB, VC, VD, VG, VM & 6 \\
\hline VG & VE, VD, VF, VM & 7 \\
\hline VH & VK, VL, VI, VJ, VE, VC & 7 \\
\hline VI & VH, VL, VE, VB, VJ, VK, VM & 6 \\
\hline VJ & VE, VH, VI, VK, VM, VD, VL & 6 \\
\hline VK & VH, VL, VJ, VM, VI, VD & 6 \\
\hline VL & VH, VI, VM, VK, VD, VJ & 6 \\
\hline VM & VL, VJ, VK, VI, VF, VG & 7 \\
\hline
\end{tabular}

Berdaasarkan tabel di atas adapun alur kerja algoritma Welch Powell adalah sebagai berikut

1. Pilih verteks berderjat paling tinggi yaitu VD dan beri dengan warna merah.

2. Pilih verteks yang tidak bertetangga dengan VD yaitu VH, VI, VM dan diberi warna yang sama dengan VD yaitu merah.

3. Pilih verteks berderjat paling tinggi selanjutnya yaitu VB dan beri dengan warna kuning.
4. Pilih verteks yang tidak bertetangga dengan VB yaitu VG, VJ, VK, VL dan diberi warna yang sama dengan $\mathrm{VJ}$ yaitu kuning

5. Pilih verteks berderjat paling tinggi selanjutnya yaitu VC dan beri dengan warna bitu

6. Pilih verteks yang tidak bertetangga dengan VC yaitu VA, VE, VF dan diberi warna yang sama dengan $V L$ yaitu kuning.

Berikut tabel Pewarnaan Graf dengan Algoritma Welch Powell yang disajikan pada Tabel 4. 
Tabel 4. Pewarnaan Graf dengan Algoritma Welch Powell

\begin{tabular}{|l|l|l|}
\hline Verteks & Derajat & Warna \\
\hline VD & 9 & Merah \\
\hline VB & 7 & Kuning \\
\hline VI & 7 & Merah \\
\hline VJ & 7 & Kuning \\
\hline VL & 6 & Kuning \\
\hline VC & 6 & Biru \\
\hline VE & 6 & Biru \\
\hline VF & 6 & Biru \\
\hline VH & 6 & Merah \\
\hline VK & 6 & Kuning \\
\hline VM & 6 & Merah \\
\hline VA & 4 & Biru \\
\hline VG & 4 & Kuning \\
\hline
\end{tabular}

Berdasarkan hasil algoritma Welch Powell diperoleh 3 kombinasi warna atau dapat dikatakan graf tersebut memiliki bilangan kromatis 3. Adapun yang dapat dihasilkan dari proses algoritma tersebut adalah :

1. Dari 13 customer service dapat dibentuk 3 tim mobile selling.

2. Tim 1 terdiri dari empat orang tim yaitu $\mathrm{D}, \mathrm{H}, \mathrm{I}, \mathrm{M}$

3. Tim 2 terdiri dari lima orang tim yaitu $B, G, J, L, K$

4. Tim 3 terdiri dari empat orang tim yaitu $A, C, E, F$

Salah satu aplikasi dari pewarnaan graf adalah masalah optimasi. Dalam kasus ini aplikasi konsep pewarnaan graf digunakan untuk menyelsaikan masalah pembagian jadwal karyawan. Salah satu algoritma yang dapat digunakan terkait masalah optimasi sistem penjadwalan adalah Algoritma Welch Powell. Berdasarkan hasil yang diperoleh dengan mengaplikasikan algoritma Welch Powell dari jadwal customer service yang telah disusun, pembagian tim mobile selling dapat disederhanakan menjadi 3 tim. Optimasi jadwal dan tim mobile selling sangat dibutuhkan karena terkait permasalahan kendaraan operasional dan pembagian proses pelayanan customer di gerai.
Adapun constraint yang ditetapkan dalam pembagian tim adalah sebagai berikut:

1. Tim terdiri dari 4-5 tim

2. Dalam satu hari ada 2 -3 orang dalam tim yang akan melakukan mobile selling secara bergiliran.

3. Dalam satu tim shift kerja CS harus berbeda atau minimal ada dua CS yang berada dalam satu shift yang sama di hari tersebut.

4. Dalam satu hari hanya ada satu tim yang melakukan mobile selling, sehingga tim yang akan melakukan kegiatan mobile selling setiap harinya akan di rolling.

Jika dilihat dari analisis constraint, hasil dari algoritma Welch Powell berhasil tidak melanggar constraint yang telah ditetapkan. Berdasarkan hasil algoritma Welch Powell, dapat dilihat bahwa dalam satu hari setiap tim yang melakukan mobile selling terdiri 2-3 orang dan dengan shift kerja yang berbeda. Berdasarkan hasil tersebut, penerapan algoritma Welch Powell dapat memberikan solusi dari permasalahan optimasi penjadwalan terutama dalam pembagian tim kerja di Gerai Indosat Ooredoo cabang Kuta. 
DAFTAR PUSTAKA

Astuti, S., 2011. Penyusunan Jadwal Ujian Mata Kuliah Dengan Algoritma Pewarnaan Graf Welch Powell. Jurnal Dian, 11(1).

Budiman, H., 2007. Penerapan Graph Colouring untuk Merencanakan Jadwal. Tersedia: $\quad$ http://www. informatika. org/ rinaldi/Matdis/2007/2008/Makalah/ MakalahIF2153-0708-025. pdf.

Hignasari, L.V. and Mahira, E.D. 2018. Optimization of Goods Distribution Route Assisted by Google Map with Cheapest Insertion Heuristic Algorithm (Cih). Sinergi: Jurnal Teknik Mercu Buana, 22(2), pp.132-138.

Liyandari, L., Rachmawati, H. and Sari, R.P., 2014. Aplikasi Penjadwalan Perawat dengan Metode Pewarnaan Graph (Studi Kasus: RSUD Arifin Achmad
Pekanbaru). Jurnal Komputer Terapan, 3(2).

Aksara

Mahardika, F. and Marcos, H., 2017. Penerapan Algoritma Graf Welch Powel Pada Penjadwalan Mata Kuliah Dan Jadwal Asisten Study Kasus Forum Asisten Stmik Amikom Purwokerto. Simetris: Jurnal Teknik Mesin, Elektro dan IImu Komputer, 8(2), pp.825-832.

Munir, Rinaldi. (2005). Matematika Diskrit edisi Ketiga,I Bandung: Informati.

Riau, K.H.S.A. 2017. Modifikasi Algoritma Welch-Powell Untuk Optimalisasi Penjadwalan Ujian Skripsi. Jurnal Teknologi dan Sistem Informasi Univrab, 2(1), hal 119-128.

Sianipar, Y., 2014. Aplikasi Pewarnaan Graf Terhadap Penyusunan Jadwalkaryawan Di Rsup H. Adam Malik Medan (Doctoral dissertation, UNIMED). 